\title{
Ser y deber ser como fundamento de las críticas de Bruno Leoni a Hans Kelsen
}

\section{Is and ought as the basis of Bruno Leoni's criticism to Hans Kelsen}

\section{Daniela Escobar Arbeláez ${ }^{1}$}

- Recepción:19/11/2019 • Aprobación:14/04/2020 • Publicación: 15/07/2020

Para citar este artículo

Escobar Arbeláez, D. (2020). Ser y debe ser como fundamento de las críticas de Bruno Leoni a Hans Kelsen. Dos mil tres mil, 22, e208.

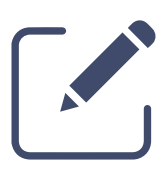
https://doi.org/10.35707/dostresmil/22208

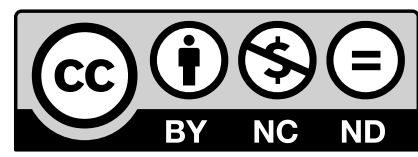

${ }^{1}$ Estudiante de Maestría en Justicia y Tutela de Derechos con énfasis en Teoría Jurídica y Filosofía del Derecho de la Universidad Externado de Colombia. ORCID: 0000-0003-3024-894X. Correo electrónico: descobararbelaez@gmail.com. 
Resumen. Este artículo presenta y contrapone las teorías del derecho de los juristas Bruno Leoni y Hans Kelsen, quienes pertenecen a diferentes corrientes jurídico-filosóficas. De esta manera, se recogen y sistematizan los cuestionamientos que el primero realizó al segundo. Así, se aborda la pregunta por el fundamento de sus críticas y se presentan los argumentos que permiten concluir que dicho fundamento es la distinción que Kelsen realizó entre el mundo del ser y el del deber ser.

Abstract. This article aims to present and contrast the theories of law of the jurists Bruno Leoni and Hans Kelsen, who belong to different legal-philosophical trends. In this way, the questions that the first asked the second are collected and systematized. Thus, it addresses the question about the basis of his criticisms and presents the arguments which allow concluding that such foundation is the distinction that Kelsen made between the world of is and ought.

Palabras claves

Teoría de la reclamación, teoría pura del derecho, ser, deber ser.

Key words

Theory of law as claim, pure theory of law, is and ought. 


\section{Introducción}

Bruno Leoni (1913-1967) fue un catedrático italiano de Filosofía del Derecho y de Teoría del Estado en la Universidad de Pavía, así como decano de la Facultad de Ciencia Política de esta universidad y fundador de la revista Il Politico. Se destacó como abogado en ejercicio, tuvo un bufete abierto en Turín y escribió diferentes textos sobre política y filosofía del derecho (Huerta de Soto, 2010). Aunque sus obras han permanecido por fuera del alcance de un público más allá de un muy limitado círculo de especialistas, llegó a ser reconocido como referente necesario al hablar de una teoría del derecho de orientación liberal (Lottieri, 2008).

Por su parte, Hans Kelsen (1881-1973) fue profesor de diferentes universidades, escribió numerosos textos y a diferencia de Bruno Leoni, su teoría del derecho se ha extendido por todo el mundo, a tal punto que gran parte de los trabajos de teoría jurídica se encuentran obligados a tenerla en cuenta (Walter, 2011).

El tema de este artículo se centra en los cuestionamientos que realizó Bruno Leoni a una de las más influyentes corrientes del pensamiento jurídico, como lo es la teoría del derecho normativista elaborada por Kelsen. De esta forma, se pretende responder a la pregunta acerca de cuál es el fundamento de estas críticas. Así, la tesis que se sostiene es que el motivo del que se derivan las críticas que hizo Leoni al positivismo normativista expuesto por Kelsen, es la distinción que este último realiza entre el mundo del ser y del deber ser.

En los siguientes párrafos se encontrará, en primer lugar, un acercamiento a la teoría pura del derecho y principales conceptos desarrollados por Hans Kelsen. En segundo lugar, se expondrán los principales conceptos y la teoría del derecho como reclamación desarrollada por Leoni. En tercer lugar, se expondrá una sistematización de las críticas que realizó Bruno Leoni al normativismo kelseniano. En cuarto lugar, se presentarán los argumentos que permiten afirmar que el fundamento de dichas críticas es la distinción entre el ser y deber ser. Finalmente, se propondrán las conclusiones.

\section{Punto de partida: Pureza metódica y teoría de la norma en Kelsen}

Hans Kelsen tuvo el proyecto de elevar la jurisprudencia a la categoría de ciencia, de tal forma que elaboró una teoría del derecho que pretende liberar a la ciencia jurídica de elementos extraños; es decir, de carácter ideológico, ético-político y sociológico (Schmill, 2010). El objeto de estudio de esta teoría es la norma jurídica, así como sus elementos y su interpretación. Sin embargo, Kelsen no estaba interesado en estudiar los contenidos de las normas jurídicas, sino en describir su estructura formal. Por ende, realizó un análisis estructural del derecho positivo, antes que una valoración de carácter moral o política de sus fines (Calsamiglia, 1997). En sus obras consideró que la ciencia jurídica debía describir el objeto tal como es, sin prescribir cómo debería ser (Kelsen, 1949).

Para Kelsen, una teoría del derecho debía mostrar la diferencia que hay entre la ciencia jurídica y la política, así como entre la realidad jurídica y la natural (mundo del ser), pues la 
realidad del derecho no se manifiesta en la conducta efectiva de los individuos. Siendo así, el orden jurídico determina cómo debe ser la conducta de los mismos, sin importar si su comportamiento se conforma o no con lo dispuesto. De esta manera, mientras que el proceder y las actuaciones de las personas hacen parte de una realidad natural, pues están determinados por las leyes de la naturaleza, la realidad jurídica, es decir, la existencia específica del derecho, se manifiesta como el fenómeno de positividad del mismo. Así, el objeto de la ciencia jurídica es el derecho positivo y no el derecho ideal, que es meta de la política. Por ello, el derecho positivo puede corresponder o no con el llamado derecho natural o justo.

La teoría pura del derecho insiste en mantener una distinción entre el derecho y la justicia trascendente, excluyendo esta última de su objeto. Por tanto, allí no se ve el derecho como una manifestación de una autoridad sobrenatural, sino como una técnica social específica que se basa en la experiencia humana. En consecuencia, la base del mismo no se busca en un principio metajurídico, sino en una hipótesis jurídica, esto es una norma básica que se establece gracias a un análisis lógico del pensamiento jurídico real (Kelsen, 1949).

Kelsen definió la norma jurídica como "Un juicio hipotético que expresa un vínculo específico entre un supuesto de hecho condicionante y una consecuencia jurídica condicionada” (Kelsen, 1934, p. 55). De este modo, entre supuesto de hecho y consecuencia jurídica hay un nexo lógico del deber ser. Esto evidencia que el jurista mantuvo la distinción entre sein y sollen de inspiración neokantiana; es decir, asumió que hay dos mundos: el del ser o de los hechos y la experiencia sensible y el del deber ser o mundo de las normas. En consecuencia, el derecho no puede fundamentarse en un hecho, sino en una norma fundante básica (Robles, 2011).

Es importante mencionar que el jurista austriaco entendió la regla de derecho como un mandato no psicológico; es decir, que no implica una voluntad en el sentido psicológico. La conducta que prescribe la regla de derecho es exigida sin que haya una voluntad humana que efectivamente quiera esa conducta. De esta forma, una norma expresa el hecho de que alguien debe proceder de determinada manera, pero esto no implica que otro realmente quiera o mande que este se comporte de ese modo (Kelsen, 1949). Por tanto, sostuvo que la norma expresa la idea de que algo debe ocurrir, aunque es posible que no ocurra, pero por esto la norma no deja de ser válida ni deja de obligar al individuo (Kelsen, 1969).

En este punto, es importante mencionar que el concepto de deber ser es el fundamento de la teoría del derecho de Hans Kelsen, pues la norma jurídica expresa un deber ser. Así, la norma jurídica tiene su origen en un acto de voluntad que establece una relación entre unos hechos y una consecuencia jurídica. No obstante, hay una diferencia entre el acto de voluntad y la norma, pues esta no coincide con el acto, sino que constituye su sentido.

Mediante el acto de voluntad se desea que una determinada consecuencia tenga lugar, y este querer constituye el sentido del acto de voluntad, y precisamente en eso consiste la norma. [...] la norma se configura como un sentido y ahí está su carácter ideal, en contraposición al acto de voluntad que tiene carácter fáctico. (Iniesta, 1999, p. 128). 
Ahora bien, para Kelsen en la palabra "derecho" hay un elemento común que le da un significado social importante, en tanto se refiere a "la técnica social que consiste en provocar la conducta socialmente deseada a través de la amenaza de una medida coercitiva que debe aplicarse en caso de un comportamiento contrario" (Kelsen, 1949, p. 22). Afirmó que es posible distinguir el derecho como la técnica social específica de un orden coactivo, de otros órdenes sociales que, aunque pueden tener los mismos fines, los persiguen a través de medios diferentes. Por tanto, el derecho es un medio social específico cuya reacción ante la infracción de una norma consiste en una medida coactiva impuesta por el orden, que se encuentra socialmente organizada (Kelsen, 1949).

Asimismo, en el desarrollo de su teoría, el jurista austriaco diferenció entre las nociones de validez y eficacia. Por validez entendió "la existencia específica de las normas" (p. 35), de tal forma que, decir que una norma es válida equivale a reconocer su fuerza obligatoria frente aquellos cuya conducta regula (Kelsen, 1949). Para diferenciar la validez de la eficacia, brinda el ejemplo de una norma que prohíbe el hurto, prescribiendo que todo ladrón debe ser castigado por el juez. Esta norma es válida para las personas a quienes se prohíbe el hurto y para el juez que la aplica, e incluso tiene validez en aquellos casos en que un ladrón hurta y escapa sin poder ser juzgado por el juez, pues en esta situación simplemente carecería de eficacia. Por un lado, la validez significa que las normas jurídicas son obligatorias y que los hombres deben obedecerlas y aplicarlas conduciéndose como estas lo prescriben. Por el otro lado, la eficacia quiere decir que los hombres realmente se comportan en la forma en que, de acuerdo con las normas jurídicas, deben hacerlo. No obstante lo anterior, para Kelsen entre ellas hay una relación importante, pues la norma es válida solo bajo la condición de que pertenezca a un sistema normativo que, considerado en su totalidad, es eficaz. Por tanto, a su juicio la eficacia es condición de la validez, pero no la razón de la misma (Kelsen, 1949).

Dentro de su teoría, Kelsen llegó a definir el orden jurídico como "un sistema de normas generales e individuales enlazadas entre sí de acuerdo con el principio de que el derecho regula su propia creación" (Kelsen, 1949, p. 156). En consecuencia, una norma pertenece a este orden cuando se crea de conformidad con otra. Por tanto, el individuo que estaba llamado a crear derecho era el órgano de la comunidad determinado por un precepto de derecho. Al tener en cuenta esto, el fundamento de validez de una norma está en que se presupone la existencia de otras normas cuya validez se admite. En consecuencia, la búsqueda del fundamento de validez de una norma no nos conduce a una realidad, sino a otra norma de la que la primera procede (Kelsen, 1949).

De conformidad con lo anterior, en un ejercicio de regresión, se llega a una norma que no deriva su validez de otra superior, a la que Kelsen denomina norma fundamental. Por tanto, todas las normas cuya validez puede ser referida a una y la misma norma fundamental, constituyen el orden o sistema normativo. Esta norma con una naturaleza especial hace las veces de vínculo que une las diversas normas que integran un orden y es norma suprema, en tanto 
representa la última razón de validez dentro de un sistema normativo. De esta forma, el fundamento de validez de las normas consiste en presuponer la existencia de una última norma (fundamental), igualmente válida (Kelsen, 1949).

Ahora bien, desde la perspectiva de Kelsen, si en esta regresión se llega a la Constitución y se inquiere por su validez, su fundamento puede estar en una Constitución más antigua y si se sigue, se va a llegar a la primera Constitución. En este punto, la validez de esta primera Constitución es el supuesto último del que depende la validez de todas las normas del sistema jurídico. De esta forma, esta norma prescribe que es deber conducirse de la forma en la que lo ordenaron quienes establecieron la primera Constitución. Así, la primera Constitución es una norma obligatoria, solo a condición de que la norma básica se suponga válida (Kelsen, 1949). En otras palabras, la última hipótesis del positivismo está en la norma básica de la cual derivó su autoridad el primer legislador, de tal manera que la función de dicha norma consiste en conferir el poder creador de derecho al acto del primer legislador y a los que en él se basen. Interpretar tales actos como jurídicos y su producto como normas que obligan, solo es posible a condición de que la norma básica se presuponga válida. Por tanto, esta norma es el supuesto necesario de la interpretación positivista del material jurídico y no es válida por ser creada de cierto modo, sino porque se supone que es válida (Kelsen, 1969).

Hasta acá se presentaron los conceptos básicos que integran la teoría del derecho desarrollada por Hans Kelsen. A continuación se presentan los principales conceptos desarrollados por Bruno Leoni.

\section{Lo planteado por Bruno Leoni}

Se ha reconocido que el aporte esencial de Bruno Leoni a la filosofía del derecho radica en su concepción del derecho como un producto evolutivo y consuetudinario y en sus críticas a la legislación y a la concepción kelseniana del Derecho (Huerta de Soto, 2010). El pensamiento jurídico-filosófico de este jurista se ha caracterizado como antiformalista, pues presenta una firme oposición al normativismo de Hans Kelsen, a través de la elaboración de una teoría del derecho que pone sus ojos en la conducta del individuo y en las relaciones interpersonales que se forman espontáneamente en la realidad social, lo cual lo acerca al realismo jurídico (Menocci, 2003). Leoni adopta una perspectiva sociológica que propone una recuperación del derecho natural, pues las cuestiones de justicia deben armonizar con lo que resulta estable en la sociedad en un momento dado (Masala, 2003). Así, es posible entender la teoría de Leoni como una reflexión individualista dentro la filosofía del derecho que aspira a establecer una alianza entre los principales adversarios del positivismo: realismo e iusnaturalismo.

Bruno Leoni observa que la palabra "ley" o "derecho", no tienen un significado que se refiera directa y exclusivamente a un objeto de experiencia sensible. Para indagar sobre la naturaleza del derecho, la definición de esta palabra requiere una metodología diferente, en tanto es necesario prestar atención al significado atribuido a la palabra "ley" por las personas que emprenden 
acciones teniéndolas en mente. De esta forma, propone buscar un elemento mínimo común en todos los usos posibles de dicha palabra (Leoni, 1961). La estrategia metodológica que Leoni adopta aquí tiene importantes implicaciones sustantivas, pues a diferencia de Kelsen, quien reduce el estudio de la ley al de la estructura lógica de las normas, el primero intenta buscar la esencia del derecho en la realidad jurídica, centrándose en los comportamientos de las personas y en los fines subjetivos. Por consiguiente, abandona la suposición de que la norma es anterior a cualquier razonamiento sobre la naturaleza de la ley y adopta la idea de que el origen de la misma se remonta a los comportamientos de los individuos (Bertolini, 2015).

A juicio de Leoni, así como un economista busca las conexiones que hay entre las acciones de los agentes económicos y los precios de los bienes que compran o venden, la tarea del filósofo del derecho es reconstruir las relaciones que hay entre los agentes jurídicos y las normas que estos pueden invocar a la hora de conseguir sus propósitos. Por consiguiente, para un filósofo del derecho las normas no pueden convertirse en los datos últimos del proceso legal, así como tampoco lo son los precios para un economista. Al seguir ello, cuando un filósofo del derecho llegue a las acciones de los individuos, se encontrará con las reclamaciones (Leoni, 1961).

Por ende, Leoni observa que identificar el significado común de la palabra "ley" con la norma jurídica sería una definición demasiado estrecha, mientras que el concepto de reclamación corresponde mejor a la idea del mínimo significado común que se le da a esta palabra. Así, el mundo del derecho se presenta ante todo como un mundo de reclamaciones. De esta forma, Leoni define la reclamación como "un hecho psicológico y como tal, un dato de la indagación empírica” (Leoni, 2003, p. 67). En la reclamación está implícita la voluntad, por parte del reclamante, de imponer una línea de conducta a otros. Esto se evidencia en situaciones tales como la ejecución de un contrato, reclamaciones por indemnización de perjuicios, la orden de un juez, entre otras (Leoni, 2003).

Leoni nota que la reclamación se refiere a comportamientos previstos como posibles y no necesarios. Así, los individuos tienen interés en que en algunas situaciones ciertos comportamientos sean adoptados por otros, y por esto añaden a la previsión una reclamación (Leoni, 2003). La voluntad del autor de la reclamación puede analizarse en términos de previsiones. En consecuencia, el autor de la reclamación prevé que cuando el comportamiento objeto de la reclamación no es adoptado por la persona destinataria, es posible obligarla a acoger ese comportamiento y también, que esta constricción puede ser realizada por otras personas. Por tanto, en cuanto se pretende que otra persona adopte un comportamiento, se suelen efectuar una serie de previsiones relativas no solo a la posibilidad de que asuma el comportamiento querido, sino a la de que otras acepten, cuando sea el caso, comportamientos idóneos para obligar a la persona a ese comportamiento. Por lo tanto, toda reclamación puede descomponerse en varias, en las que tienen parte determinadas previsiones (Leoni, 2003). Por ejemplo, X reclama que su deudor, Y, le pague. El objeto de esta reclamación es un comportamiento determinado del deudor consistente en el pago de la deuda. Este comportamiento es posible, pero no necesario. Si X piensa 
obligar a Y a pagarle, realizará una reclamación y preverá que otras personas intervengan, al asumir comportamientos que fuercen al deudor a pagar.

En lo anterior se evidencia una relación muy estrecha entre lo positivo y las previsiones científicas que erróneamente, a juicio de Leoni, no admiten quienes contraponen rígidamente el mundo del derecho al de la ciencia natural. Así, el jurista considera que no existe un abismo entre el mundo jurídico (mundo de las reclamaciones) y el mundo de la ciencia natural, como un mundo de datos previsibles, en cuanto el contenido de lo positivo es el de una previsión; es decir, se liga con previsiones que se refieren al mundo efectivo (Leoni, 2003).

Resulta importante mencionar que las reclamaciones o pretensiones se basan en previsiones, aunque no son reducibles a estas. Por lo tanto, la posición del agente jurídico no es la misma de, por ejemplo, un científico que prevé un evento natural, pues el agente jurídico desea que suceda el acontecimiento por razones propias y, al mismo tiempo, puede influir en dicho acontecimiento mediante su actuación. En consecuencia, ninguna reclamación es posible sin un elemento de voluntad. Asimismo, la voluntad resulta posible en tanto se basa en la previsión mencionada (Leoni, 1961). Un ejemplo que sirve para entender esto es el de un acreedor que prevé que su deudor le pagará, pero además de esto también desea que le pague, por esto está determinado a emplear ciertos medios a su disposición para lograrlo. Acá hay una voluntad del acreedor de conseguir un comportamiento que él prevé como estadísticamente probable por parte de otras personas (Leoni, 1961). Por consiguiente, Leoni denomina reclamaciones jurídicas a

Aquellas exigencias o pretensiones que tienen una alta probabilidad de ser satisfechas por las personas a quienes corresponde en una sociedad dada y en cualquier momento dado, siendo variables y estando basadas alternativa o conjuntamente en normas morales o técnicas las razones por las cuales pudieran satisfacerse en cada caso concreto. (Leoni, 1961, p. 222).

Por esta razón, el proceso jurídico, en un último término, se remonta a la reclamación individual. Los individuos crean el derecho en cuanto efectúan reclamaciones que prosperan. Estos individuos hacen previsiones y predicciones e intentan que estas tengan buen fin mediante su propia intervención en el proceso. Así, los jueces, jurisconsultos y legisladores, son individuos que se encuentran en una situación especial para influir, a través de su propia intervención, en todo el proceso jurídico (Leoni, 1961). En otras palabras, a juicio de Leoni, en las sociedades se presenta el encuentro entre reclamaciones hechas por individuos y esa relación social originaria es la que da origen a las normas. Los individuos en ocasiones pueden alegar reclamaciones dentro de un universo poblado por otros sujetos, que también son portadores de reclamaciones (a veces incompatibles), y del encuentro de las reclamaciones que son compatibles y conciliables entre sí, brotan las reglas de la vida social que nos imponen; por ejemplo, no agredir al prójimo, pagar a los acreedores, etc. (Lottieri, 2003).

Ahora bien, Leoni diferencia entre reclamaciones jurídicas e ilegales. Las primeras, como se dijo anteriormente, son las pretensiones que tienen una probabilidad alta de ser satisfechas 
por las personas a quienes corresponde en una sociedad en un momento dado. Por el contrario, las exigencias o pretensiones ilegales son aquellas que tienen poca o ninguna probabilidad de resultar satisfechas por las personas a quienes corresponde en circunstancias normales (Leoni, 1961).

\section{Críticas de Bruno Leoni a Hans Kelsen}

A continuación nos referiremos a las críticas que Bruno Leoni realizó al positivismo normativista expuesto por Hans Kelsen. A grandes rasgos, es posible establecer que a su juicio, Kelsen no explicó de manera exhaustiva los conceptos sobre los que fundamenta su teoría del derecho; se llevó la impresión de que las ideas fundamentales del sistema kelseniano no llegaron a ser suficientemente profundas (Leoni, 2003).

\subsection{Ser y deber ser}

A juicio de Leoni (2003), no es posible encontrar en Kelsen una profundización en la diferenciación que realiza entre ser y deber ser (sein y sollen) y precisamente aquí radica el principal defecto de toda su teoría. Esta falta de profundización desemboca en que el deber ser termina convirtiéndose en un ser, pues el normativista contempla a la norma como un objeto de estudio, de la misma forma que un sociólogo o un físico contemplan un hecho social o un hecho físico respectivamente como el suyo. Así, al no estudiar la relación entre ser y deber ser, el teórico de la norma termina adoptando una lógica y metodología igual a la de quien estudia cualquier otro objeto. Por consiguiente, para Leoni, el problema de la teoría de Kelsen es que en ella la norma termina volviéndose un dato de estudio, como cualquier otro fenómeno o elemento de la naturaleza. Leoni reconoce que en el momento en que la norma prescribe, decimos a nosotros mismos "debo comportarme así", lo cual efectivamente es diferente a decir "es así". No obstante, pone de presente que si se examina el hecho de que la norma prescribe o "manda", nos encontramos que este hecho es un dato de estudio (Leoni, 2003).

De igual manera, Leoni (2003) reconoce que la falta de profundización en los significados de ser y deber ser y en su relación, es aún más grave si se tiene en cuenta que las normas jurídicas se enuncian con frecuencia con fórmulas lingüísticas que no implican el empleo del término deber. Esto se vuelve evidente si se tiene en cuenta que la generalidad de las normas legislativas no se enuncia mediante el uso del verbo deber (sollen), sino mediante el uso del verbo ser (sein) conjugado en el presente indicativo o en el futuro indicativo. Al tener en cuenta esto, concluye que Kelsen no entiende el deber ser como una expresión lingüística que es necesariamente expresada en las normas, sino como

Expresión lingüística que él emplea para expresar su noción de las normas, es decir, para expresar lo que las normas significan (algo que no es, sino que debe ser), aunque luego el significado kelseniano de las normas como deber ser no se explica nunca, sino que se acepta como evidente. (Leoni, 2003, p. 217). 
Leoni pone de presente que no es posible atribuir al término deber ser (sollen) el mismo significado que en su momento le dio Kant, cuando aludía con el mismo a los hechos de la conciencia que son imperativos morales, pues Kelsen observó que las normas jurídicas no son hechos de la conciencia. El jurista italiano se pregunta: si el deber ser no es un hecho de conciencia ni una fórmula lingüística con la que se expresan habitualmente las normas, ¿qué es entonces? e identifica aquí el punto fundamental que, a su juicio, Kelsen dejó en la sombra. Así, llega a concluir que toda su teoría del derecho se basó en el concepto de deber ser (sollen), que no se sabe bien en qué consiste (Leoni, 2003).

Como se explicó anteriormente, en la construcción de su teoría, Kelsen pretendió mantenerse en un terreno del deber ser. Con el fin de no hallarse en el mundo del ser, al que pertenecen otras ciencias, rechazó la teoría de la norma como mandato, pues de aceptar que la norma es un mandato, estaría frente a un hecho psicológico; es decir, un elemento de la realidad social. De esta forma, definió a la norma como un mandato no-psicológico (Kelsen, 1949). Acá radica otra de las críticas de Bruno Leoni, quien pone de presente que si se hablara de un simple mandato, este podría entenderse como un hecho psicológico o como una fórmula lingüística; no obstante, si se habla de un "mandato des-psicologizado" no es ni lo uno ni lo otro, lo cual dificulta entender qué es la norma (Leoni, 2003).

Bruno Leoni supone que quizá Kelsen entendía las normas jurídicas como significados pensados, pero separados de la persona que los piensa. No obstante, luego afirma que dicha postura no es sostenible, pues los textos escritos son objetos físicos y el significado, entendido como algo que es pensado, no es autónomo porque presupone que alguien lo piensa. Sería inexacto decir, por ejemplo, que los signos dejados en un papel tienen una autonomía propia. Así, Leoni considera equivocado el aislamiento de la norma como algo en sí mismo. A su juicio, si Kelsen quisiera combatir a los sociólogos, que identifican el derecho en los comportamientos de las personas, les diría que si consideran los comportamientos de las personas, deben siempre referirse a las normas que las personas tienen en mente cuando se comportan. No obstante, las normas que las personas tienen en mente no son mandatos des-psicologizados, sino que son hechos psicológicos (Leoni, 2003). Y, concluye:

El punto crítico de toda la teoría de kelseniana de la norma es precisamente esta norma que no es un ser, que es un deber ser, que no se sabe en qué consiste, que quisiera ser autónoma respecto a los pensamientos de las personas, que en realidad no lo es nunca, a no ser que se considere como un conjunto de signos sobre el papel. Naturalmente, esta teoría no es ya equívoca cuando decimos que la norma es esa cierta actitud mental que tiene una persona cuando hace una determinada cosa; pero entonces la norma es un hecho psicológico. (Leoni, 2003, p. 221).

\subsection{Validez y eficacia}

Como se explicó anteriormente, Kelsen (1949) entiende por validez la existencia específica de las normas, de tal forma que afirmar que una norma es válida significa decir que asumimos que 
tiene fuerza vinculante para aquellos cuya conducta regula. Frente a esto, Leoni sostiene que no consigue ver en la teoría de Kelsen una explicación suficiente acerca de cómo concibe esta fuerza obligatoria o vinculante, pues aunque pareciera que la concibe como sollen, no se analiza el concepto de manera profunda (Leoni, 2003). Además, se pregunta quién atribuye esta fuerza a la norma. De manera más específica, no comparte que Kelsen simplemente identifique la norma con algo que debe ser, pues dicha explicación no dice nada acerca de la fuerza vinculante, sino que remite a los hechos psicológicos. Por tanto, nunca se sabe de manera concreta qué son las normas, pues no son eventos psicológicos, ni datos de la experiencia moral, ni hechos.

Dentro de la teoría de Kelsen (1949) se sostiene que las normas son jurídicas en cuanto tienen validez y prescriben una sanción. Esta validez se entiende como su existencia específica. Acá Leoni (2003) se cuestiona qué significa que existan normas y brinda el ejemplo de las normas del Código de Hammurabi, pues aunque no son eficaces, son válidas, en tanto tienen la forma de deber ser y están dotadas de sanciones. Ahora bien, cuando consideró dichas normas, Kelsen sostuvo que ya no eran válidas, en cuanto las personas no asumen su existencia ni las consideran dotadas de fuerza vinculante. Acá, Leoni se pregunta qué puede significar asumir las normas como dotadas de fuerza vinculante, si no es un elemento psicológico, pues aunque se puede considerar la capacidad de vincular como un concepto abstracto, esta abstracción se basa en eventos de naturaleza psicológica. Por consiguiente, Leoni llega a concluir que Kelsen no logra nunca explicar en qué consiste la validez, que se supone es distinta de la eficacia (Leoni, 2003).

Ahora bien, para Kelsen (1949), si la norma deriva de una autoridad legítima, es una norma legal, válida y vigente. En otras palabras, una norma que emana de una autoridad legislativa es una norma legal porque proviene de una autoridad legítima que ha legislado del modo establecido. Así, tras haber tratado de fundamentar toda la teoría del derecho sobre una teoría de la norma sin referencia a la eficacia, Kelsen creó su propio sistema e introdujo su concepto de orden jurídico al que las normas pertenecen, admitiendo que la Constitución no representa la norma básica, sino que se basa en el consenso de los ciudadanos (Leoni, 2003). En este punto, Leoni acusa a Kelsen de haberse visto obligado a admitir que una norma es válida, de forma indirecta, porque el orden legal es eficaz; en otras palabras, porque las personas, aunque pueden no aceptar una norma particular, aceptan el conjunto de normas en general (Leoni, 2003).

Finalmente, Leoni critica el concepto kelseniano de "validez excluyente" del orden nacional; esto es, excluyente de cualquier ordenamiento distinto. En este punto, el jurista italiano se cuestiona para quién es excluyente, pues así como hay quienes aceptan y solo consideran eficaz el orden legal nacional, también están los que admiten las normas de otro orden que no es el del Estado y se comportan conforme a ellas (Leoni, 2003).

\subsection{Norma fundamental}

Ahora bien, Leoni considera que Kelsen en su intento de diferenciar la norma fundamental de las demás normas, ha transformado, de manera inadvertida, un problema conceptual en un 
problema pseudo-histórico. De esta manera, razona que es extraño que Kelsen reflexionara que para determinar la validez de la Constitución es necesario remontarse a su vez a otra más antigua, pues una Constitución no puede conferir validez a otra, convirtiéndose así en una súperconstitución. La crítica de Leoni va más allá cuando, frente a la afirmación de Kelsen, según la cual, por último se llega a una Constitución que es históricamente la primera y fue otorgada por un usurpador individual o por una asamblea cualquiera, sostiene que se puede objetar que si se trata del caso de un usurpador, este es una autoridad ilegítima según una norma precedente. De este modo, a juicio de Leoni, el proceso histórico acabaría solo con Adán, y en todo momento de este proceso se vuelve a plantear el problema conceptual de definir la norma fundamental y distinguirla de las demás (Leoni, 2003).

Para Leoni la norma fundamental en el sistema de Kelsen o es norma según su definición de la norma; o sea, en cuanto es puesta por autoridades legítimas, y entonces no es fundamental (porque existiría otra norma que habrá establecido cuáles son las autoridades legítimas) o bien es fundamental, y en este caso no es norma porque si está en el origen de este proceso, no puede ser puesta por ninguna autoridad legítima. Acá el jurista italiano pone de presente que si en cambio se dice que las leyes son válidas porque la gente las acepta, entonces la validez simplemente se convertiría en eficacia y la norma no sería otra cosa que un conjunto de fenómenos psicológicos que orientan el comportamiento de la gente. No obstante, si se acepta la teoría de Kelsen de la norma como algo que no pertenece al mundo del ser, la contradicción es manifiesta (Leoni, 2003). Por tanto, Leoni concluye que:

Se descubre así que el intento de prescindir de los hechos reales fracasa cuando se trata de fundamentar todo el sistema en una norma básica que luego nos vemos obligados a identificar como una especie de eficacia reconocida a la norma. (Leoni, 2003, p. 259).

En consecuencia, para Leoni lo anterior pone en crisis toda la teoría de Kelsen, pues en la relación entre ordenamiento jurídico y norma básica, introduce consideraciones cronológicas que poco tienen que ver con la distinción entre validez y eficacia. Es decir, el problema del sistema de normas, y del orden jurídico, se termina convirtiendo en un problema histórico o pseudo-histórico de la primera Constitución (Leoni, 2003).

\subsection{Derecho positivo}

Otro de los problemas que tiene Leoni con la teoría de Kelsen radica en que, dentro de la misma, la palabra positivo no siempre se emplea de un modo muy claro. Para Kelsen, el derecho es siempre derecho positivo y su positividad consiste en que es creado o anulado por actos de seres humanos, apareciendo así independiente de la moralidad y de sistemas de normas semejantes. De esta forma, esto es lo que permite diferenciar el derecho positivo del derecho natural, pues las normas del primero son creadas por determinadas autoridades, contempladas en una norma superior, mientras que las de derecho natural y moralidad, se deducen mediante una especie de inferencia lógica de alguna norma general básica o de alguna norma general precedente (Kelsen, 
1949). Ahora bien, para Leoni esta distinción vale hasta cierto punto, pues no es absolutamente cierto que las normas jurídicas no se deduzcan. Ejemplo de ello es que el juez crea una norma particular llamada sentencia a partir de una norma o regla general que aplica, y esta creación de la norma-sentencia se da a través de un proceso deductivo (Leoni, 2003). Asimismo, las leyes ordinarias tienden a ser emanadas precisamente como resultado de determinadas deducciones que los legisladores realizan partiendo de las normas constitucionales (Leoni, 2003).

Ahora bien, cuando Kelsen trata de diferenciar un deber moral de uno legal, sostiene que el deber legal se encuentra relacionado con alguna forma de coacción o con la contemplación de una posible coacción en la fórmula lingüística que expresa dichos deberes (Kelsen, 1949). No obstante, Leoni no comparte esta afirmación, pues algunas normas consideradas legales carecen de todo tipo de coacción o mención de la coacción en la fórmula que las expresa. El motivo de ello, es que si observar las normas legales dependiera de manera principal de la coacción o de la amenaza de coacción, todo el proceso se hallaría lleno de fricciones y sería tan dificultoso que no surtiría efecto. Así, observa que la teoría del derecho de Kelsen pasa por alto la importancia marginal de la coacción en el conjunto de cualquier orden jurídico real (Leoni, 1961).

\section{Fundamento de las críticas de Bruno Leoni a Kelsen}

Hasta el momento se presentaron las diferencias entre los pensamientos de Bruno Leoni y Hans Kelsen y más específicamente, las críticas que realizó el primero a la teoría del derecho del segundo. Ahora bien, es posible sostener que el fundamento de estos desacuerdos radica en la distinción entre ser y deber ser acogida por Kelsen, pues existe una conexión directa entre los elementos criticados por Bruno Leoni y esta distinción. A continuación, se proporcionarán las razones que sustentan esta postura.

\subsection{Norma jurídica como deber ser}

En primer lugar, es posible afirmar que la distinción realizada por Kelsen entre ser y deber ser derivó en un concepto de norma jurídica como deber ser y mandato no psicológico que, como se mencionó atrás, Leoni ataca por no ser claro. Esta relación directa entre la dualidad acogida por Kelsen y el concepto de norma jurídica, se explica en tanto este jurista, con el fin de no hallarse en el mundo del ser y conservar la pureza metodológica de su teoría manteniéndola en el campo del deber ser, sostuvo que la regla de derecho es un mandato de carácter no-psicológico. Esto significa que la conducta que prescribe la regla de derecho es exigida sin que efectivamente haya una voluntad humana que realmente la quiera. En otras palabras, el teórico austriaco consideraba que una norma expresa el hecho de que alguien debe proceder de determinada manera, pero esto no implica necesariamente que otro realmente quiera o mande que este se comporte de ese modo. Por tanto, llegó a declarar que la norma es una expresión de la idea de que algo debe ocurrir; es decir, de que un individuo debe comportarse de cierto modo (Kelsen, 1949). Al tener en cuenta lo expuesto de su teoría, se puede sostener que Kelsen desapareció la 
voluntad humana real del concepto de norma, porque pretendía mantener la diferencia entre el mundo de los hechos y el de lo normativo. De tal forma que al haber introducido en su concepto de norma la voluntad real de quien legisla, hubiera hecho necesario hacer referencia al mundo de los hechos, lo cual representaría un menoscabo para la pureza de su teoría.

En concordancia con lo anterior, vale la pena recordar que el mismo Bruno Leoni sostuvo que entender las normas como deber ser lleva a un limbo en el que no se sabe exactamente qué son. Por consiguiente, cuando se habla de la fuerza obligatoria de la norma que expresa un deber ser, en lo primero que se suele pensar es en los hechos psicológicos. No obstante, hablar de hechos implicaría remitirse al mundo del ser, lo cual explica que Kelsen no entendiera las normas de esta manera. Es por esto que Leoni llegó a decir que si las normas no son elementos del ser, como por ejemplo hechos de la ciencia o entes concretos, ni tampoco lo son de la moral o de la razón práctica, entonces no es posible saber qué son las normas dentro de la teoría positivista del derecho (Leoni, 2003).

\subsection{Ser y deber ser y validez y eficacia}

En segundo lugar, es posible sostener que la dualidad ser y deber ser también tiene una relación directa con las nociones de validez y eficacia, contra las cuales Leoni arremete, por no ver de manera clara la diferencia que ellas presentan en la teoría de Kelsen. Antes se mostró que Kelsen (1949) diferenció los conceptos de validez y eficacia, al sostener que, mientras el primero significa que las normas jurídicas son obligatorias y que los hombres deben conducirse como estas lo prescriben, el segundo quiere decir que los hombres realmente se comportan de la forma en que, según las normas jurídicas, deben hacerlo. Por consiguiente, veía la validez como una cualidad de las normas jurídicas y de la eficacia como una cualidad de la conducta de los hombres, que no interesa al derecho, sino a las ciencias empíricas. Así, es posible sostener que esto obedece a la pretensión de marcar una diferencia clara entre el ámbito normativo o prescriptivo, al que pertenece el derecho, y el ámbito de lo empírico, que es objeto de estudio de otras disciplinas. En consecuencia, mientras que en el ámbito prescriptivo se habla de la validez, en el empírico se habla de eficacia. No obstante, como se vio, Leoni demuestra a través de sus argumentos cómo estos dos conceptos terminan entrelazados, lo cual evidencia la contradicción en la que cayó Kelsen.

\subsection{Ser y deber ser y norma fundamental}

En tercer lugar, es posible afirmar que hay una relación entre la dualidad ser y deber ser y el concepto de norma fundamental, tan problemático para Leoni. Esto se evidencia, en tanto el mismo Leoni (2003) afirmó descubrir que el intento de Kelsen de prescindir de los hechos reales en su teoría; es decir, de mantener la distancia entre el mundo de los hechos o lo real y el normativo, fracasa en el momento en que decidió fundamentar su sistema en una norma básica que pareciera terminar identificándose con una especie de eficacia. Lo anterior obedece a que 
Kelsen afirmó que cuando se establece un nuevo orden jurídico que empieza a ser eficaz en la generalidad de los casos, entonces este orden es válido y la conducta de los individuos será entonces interpretada como legal o ilegal con base en el nuevo orden. Esto se traduce en que se presupone la existencia de una nueva norma básica que ya no es aquella de acuerdo con la cual la vieja Constitución tenía validez, sino de una nueva norma de acuerdo con la cual es válida la nueva Constitución Republicana (Kelsen, 1949). Así, al sostener que la validez de la norma fundante básica que une a todas las demás del ordenamiento jurídico depende de un comportamiento general de las personas, se desdibuja la distancia o diferencia que hay entre validez (cualidad de las normas) y eficacia (cualidad de la conducta de las personas) y por ende, la que hay entre el mundo de los hechos y de lo normativo.

\subsection{La convicción de que el mundo del derecho no es diferente al de las ciencias naturales} En cuarto lugar, es importante rescatar que para Bruno Leoni, a diferencia de Kelsen, no existe un abismo entre el mundo jurídico. Esto es, el mundo de las reclamaciones, y el mundo de la ciencia natural, como un mundo de datos previsibles, pues encuentra una relación muy estrecha entre lo positivo y las previsiones científicas que realizan los individuos al efectuar una reclamación. Esto, en tanto la voluntad del autor de la reclamación puede analizarse en términos de previsiones. Siendo así, el autor de la reclamación prevé que cuando el comportamiento objeto de la reclamación no es adoptado por la persona destinataria (por ejemplo, el deudor no paga), es posible obligar a esa persona a ese comportamiento y también que esta constricción puede ser realizada por otras personas. Por tanto, en cuanto se pretende que otra persona asuma un comportamiento, se suelen efectuar una serie de previsiones relativas no solo a la posibilidad de que adopte la conducta sino a la de que otras acojan, cuando sea el caso, las medidas idóneas para obligar a esa persona a admitirla (Leoni, 2003). Por consiguiente, resulta evidente que el principal problema que identificó Leoni en la teoría de Kelsen - y del que derivan los demáses su creencia acerca de que el mundo del derecho, es decir el del deber ser diferente al del ser, dista del mundo de las ciencias naturales, pues él sí tiene la firme convicción de que existe una relación muy estrecha entre ambos.

Además, acoger la diferenciación entre estos dos mundos y entender la naturaleza de las normas como parte del deber ser, conllevaron a que Kelsen pensara la naturaleza prescriptiva de las normas como el dato último del proceso jurídico. Acá radica una de las principales diferencias entre Kelsen y Leoni, pues este último considera que para un filósofo del derecho, la naturaleza prescriptiva de una norma no puede ser el dato último del proceso jurídico. Leoni tiene la convicción de que el filósofo del derecho está llamado a reconstruir las relaciones que existen entre los agentes jurídicos y las normas que estos invoquen en aras de conseguir sus propósitos, de la misma manera que el economista debe descubrir las relaciones que hay entre las acciones de los diferentes agentes económicos y los precios (Leoni, 1961). Esto último resultaría inconcebible para Kelsen, pues estudiar las relaciones entre los agentes jurídicos y las normas no 
sería una tarea propia del científico del derecho, sino de otra ciencia que en lugar de normas, se encargue de estudiar los hechos y la realidad, como por ejemplo, la Sociología.

\subsection{La lectura que Leoni hizo de Kelsen}

Finalmente, otro argumento que respalda la tesis que se ha sostenido, consiste en que el mismo Bruno Leoni pareció haber admitido que el punto central de su crítica a Kelsen radica en la distinción que este realiza en entre ser y deber ser. Leoni sostuvo que en la teoría de Kelsen las normas jurídicas no son hechos de la conciencia ni fórmulas lingüísticas, de tal forma que llegó a afirmar expresamente:

¿Qué es entonces el Sollen? He aquí un punto fundamental que Kelsen deja en la sombra. Se puede decir que toda su teoría del derecho se basa en el concepto de Sollen que no se sabe bien en qué consiste. (Leoni, 2003, p. 218).

Ahora bien, a pesar de que Leoni no hace explícita la relación que hay entre todos los problemas y contradicciones que encuentra en la teoría del derecho elaborada por Hans Kelsen y la dualidad ser y deber ser, acá sostiene que la teoría de este se basó en el concepto de Sollen. Por consiguiente, resulta evidente que si Kelsen no hubiera creído que existe un deber ser diferente al del ser, no habría llegado a entender la norma jurídica como perteneciente exclusivamente al mundo del deber ser. Así, sí resulta posible afirmar que Leoni vio en la distinción realizada por Kelsen el defecto fundamental de su teoría.

Hasta aquí se presentaron los argumentos que permiten sostener que el fundamento de las críticas que realizó Bruno Leoni a Hans Kelsen es la distancia que este último veía entre el mundo del ser y el deber ser. A continuación se presentarán las conclusiones.

\section{Conclusiones}

En el presente artículo se expusieron las teorías del derecho de los juristas Hans Kelsen y Bruno Leoni. Se evidenció un distanciamiento entre estos en la forma de acercarse al estudio del derecho. La estrategia metodológica de Leoni, quien ha sido considerado un anti-formalista de corte liberal, dista de la de Kelsen, principal exponente del positivismo jurídico. Mientras que este último redujo el estudio del derecho a las normas, el primero buscó la esencia del derecho en la realidad jurídica, al tomar como punto de partida los comportamientos de los individuos. Posteriormente, se evidenciaron las críticas que el jurista italiano realizó a la teoría normativista de Kelsen y se planteó una respuesta a la pregunta por el fundamento de estas, demostrando que se trata de la distinción entre ser y deber ser acogida por Kelsen, pues es posible establecer una conexión directa entre los elementos criticados por Bruno Leoni y esta distinción. 


\section{Referencias}

Bertolini, D. (2015). The Theory of law 'As claim' and the inquiry into the sources of law: Bruno Leoni in Prospect. Southern California Interdisciplinary Law Journal, 24, 561-606. Recuperado de https:// gould.usc.edu/why/students/orgs/ilj/assets/docs/25-1-Bertolini.pdf

Calsamiglia, A. (1997). En defensa de Kelsen. Barcelona, España: Universitat Pompeu Fabra. Recuperado de https://www.icps.cat/archivos/WorkingPapers/WP_I_129.pdf?noga=1

Iniesta, J. J. (1999). La oposición entre ser entre 'ser' y 'debe ser' en el análisis de la norma jurídica de Hans Kelsen y Norberto Bobbio. Anales de Derecho, 17, 125-142. Recuperado de https://revistas. um.es/analesderecho/article/view/81141

Kelsen, H. (1949). Teoría general del Derecho y del Estado, 1. a ed. (E. García Maynez, Trad.). México D.F: Universidad Autónoma de México.

Kelsen, H. (1934). Teoría pura del Derecho, 1. ${ }^{\mathrm{a}}$ ed. Madrid, España: Trotta.

Kelsen, H. (1969). Teoría pura del Derecho. Buenos Aires, Argentina: Eudeba.

Leoni, B. (1961). La libertad y la ley. 3. a ed. Madrid, España: Unión Editorial.

Leoni, B. (2003). Lecciones de Filosofía del Derecho. Madrid, España: Unión Editorial.

Lottieri, C. (2008). Prefacio. En B. Leoni, Lecciones de filosofía del derecho (J. M. Fuente, Trans.). Madrid, España: Unión Editorial.

Masala, A. (2003). Il liberalismo di Bruno Leoni. Soveria Mannelli: Rubbettino Editore.

Menocci, S. (2003). L'Antiformalismo di Bruno Leoni nei suoi rapporti con le correnti del Realismo Giuridico. Siena: Dipartamento di Scienze Politiche e Internazionali.

Robles, G. (2011). Presentación. En H. Kelsen, Teoría pura del Derecho (pp.9-32). Madrid, España: Trotta.

Huerta de Soto, J. (2010). Prólogo. En B. Leoni, La libertad y la ley (pp.9-17). Madrid, España: Unión Editorial.

Schmill, U. (2010). Hans Kelsen: Aportaciones teóricas de la Teoría Pura del Derecho. Doxa: Cuadernos de Filosofia del Derecho, 33, 18-36. Recuperado de https://doxa.ua.es/article/view/2010-n33-hanskelsen-aportaciones-teoricas-de-la-teoria-pura-del-derecho

Walter, R. (2011). Hans Kelsen vida y obra. Una introducción. Anales, 41, 332-337. Recuperado de http:// sedici.unlp.edu.ar/handle/10915/20721 